\title{
A Review of Single-Mode Fiber Optofluidics (Invited)
}

\author{
R. Blue, Member, IEEE, A. Duduś, and \\ D. Uttamchandani, Senior Member, IEEE
}

\begin{abstract}
We review the field we describe as "single-mode fiber optofluidics" which combines the technologies of microfluidics with single-mode fiber optics for delivering new implementations of well-known single-mode optical fiber devices. The ability of a fluid to be easily shaped to different geometries plus the ability to have its optical properties easily changed via concentration changes or an applied electrical or magnetic field offers potential benefits such as no mechanical moving parts, miniaturization, increased sensitivity and lower costs. However, device fabrication and operation can be more complex than in established singlemode fiber optic devices.
\end{abstract}

Index Terms - Optofluidics, single-mode fiber, optical devices

\section{INTRODUCTION}

$\mathrm{T}$ HE distinct scientific disciplines of optics and microfluidics has seen convergence in recent years to create a new area of active research that has become known as optofluidics [1]. Optical devices have been traditionally based on solid materials such as glasses and plastics; however, these are less amenable to geometric or refractive index modification in-situ than a liquid. One of the primary research goals in engineering and science is the miniaturization of systems and components, where small size and weight, low power consumption and low manufacturing cost are considered as advantages. Optical measuring, communication and imaging devices can benefit from these advantages. Optofluidics integrates microfluidics with optical systems and exploits the unique properties of fluids to achieve new methods of light manipulation, which can lead to lower cost, smaller, optical devices with lower operating voltages, no moving mechanical parts, added functionality and potentially enhanced performance [2]. Fiber optic devices are popular due to their small size, high sensitivity, and remote sensing ability.

In this paper we will focus on a sub-set of the field of optofluidics, which we call "single-mode fiber optofluidics". Single-mode fiber optofluidics is the combination of microfluidics technology with single-mode fiber (SMF) technology to yield fiber optic devices having filtering, attenuating and sensing functionalities. The ability of a fluid to mould itself to the varied geometries of optical fiber platforms

Manuscript received May 30, 2015.

R. Blue, A. Duduś, and D. Uttamchandani are with the Centre for Microsystems and Photonics, University of Strathclyde, Glasgow, Scotland, UK.

(corresponding author email: d.uttamchandani@strath.ac.uk). together with its ability to readily change its optical properties are distinct advantages which promote the development of SMF optofluidic devices. In general SMF devices can be classified into continuous fiber devices and fiber-gap devices. This classification also extends to SMF optofluidic devices. In this paper we review the full range of SMF optofluidic devices reported to date. Sections II and III examine the modifications required to the standard SMF to achieve interaction of a fluid with the guided light for both continuous fiber and fiber-gap devices. Section IV highlights fluids with variable optical properties that are employed in these devices, whilst Section V onwards summarizes the wide range of devices achieved to date in this relatively new field of research.

\section{CONTINUOUS FIBER DEVICES}

Continuous fiber devices are devices in which the optical fibers retain the axial (longitudinal) continuity of the fiber core from input to output. This family of fiber devices eliminates the need for light to leave the input fiber, have its properties modified in some manner and then re-enter the output fiber. Continuous fiber devices can therefore offer lower insertion and return losses compared to other fiber devices. There are two general ways to realizing continuous fiber devices using SMF. The first general way is through control of the mode index (effective index) of the fiber mode in real-time. This can be achieved by changing the optical refractive index of the cladding immediately surrounding the fiber core. Access to the mode field requires re-engineering the basic structure of the SMF in a relatively simple way. Standard SMF consists of a 9 $\mu \mathrm{m}$ core embedded at the center of a $125 \mu \mathrm{m}$ diameter cladding. Side polishing or tapering the fiber cladding, described below, enables the evanescent component of the mode field to be accessed, thereby allowing the mode index to be changed. The second general way to create continuous fiber devices is to produce photorefractive gratings in the fiber core or cladding, and then change the refractive index of the region surrounding the fiber cladding. As described below, such gratings also enable functional single mode fiber devices to be obtained.

\section{A. Side Polished Fibers (SPFs)}

In the early 1980s the optical fiber polished half-block coupler was introduced [3] but had the disadvantages of (a) generating an optical interaction length of just a couple of millimeters and (b) being a very slow fabrication process. By the late 1980s, much longer optical interaction lengths could 
be achieved using polishing wheels [4]. With the use of appropriate fluids and abrasive materials the cladding thickness of the fiber was rapidly reduced on one side to approach the fiber core while leaving the cladding on the opposite side of the fiber untouched. The untouched cladding gave the polished fiber robustness and permitted general (careful) handling, but was less robust than the polished halfblock coupler. A major advantage of this fiber polishing technique (illustrated in Fig. 1a) was the much reduced fabrication time. This enabled large-scale production and commercialization of low-loss side-polished fibers (SPFs). Fig. 1b illustrates the topology of the polished fiber region obtained using the process of Fig. 1a.

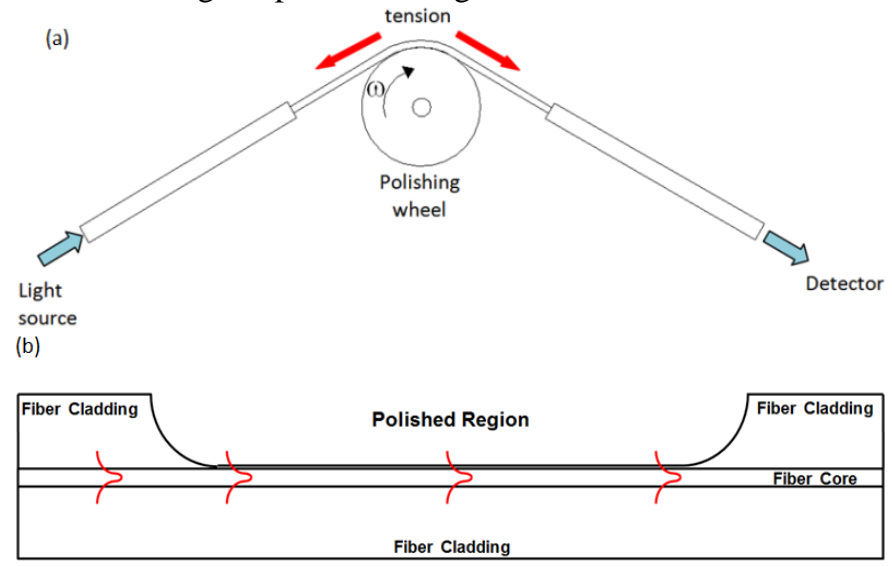

Fig. 1 (a) Depicting the polishing one side of an optical fiber with a spinning wheel. (b) Illustration of a side-polished fiber section allowing access to the optical evanescent field (not to scale).

\section{B. Tapered Optical Fibers}

An unbroken optical fiber taper can be formed by either heating and pulling or by chemically etching a length of standard SMF with buffered hydrofluoric acid. Both methods require careful control and precise halting of the process, usually by monitoring the optical power transmitted through the fiber. Typical straight fiber tapers have a waist diameter less than $10 \mu \mathrm{m}$ to gain access to the evanescent field. Duduś et al. made a comparative study of the sensitivity of SPFs and tapered fibers (Fig. 2) to changes of the refractive index of a fluid surrounding them [5]. A tapered fiber with a waist diameter of $5 \mu \mathrm{m}$ was experimentally shown to have approximately 14 times higher sensitivity to surrounding refractive index changes compared to a SPF fiber of equivalent length. This result stems from a combination of the evanescent field permeating radially from the entire surface of the fiber taper together with an increased penetration of this field into the surrounding environment due to the narrow diameter of the taper. Although decreasing the fibre waist diameter to a few microns or less can significantly increase the device sensitivity, it comes at the cost of long term mechanical and optical integrity. This occurs due to irreversible surface crack formation due to water vapour in the atmosphere and to light scattering from accumulated dust particles. Practical long term micro/nano taper devices require a method to coat and protect the device without hindering the functionality of the device, i.e. allowing interaction with the evanescent field [6]. Reported methods to achieve this have included encapsulating the device in a transparent hydrophobic porous silica aerogel [7], or within a glass capillary with holes in the wall to allow the admission of liquid and gas samples [8].

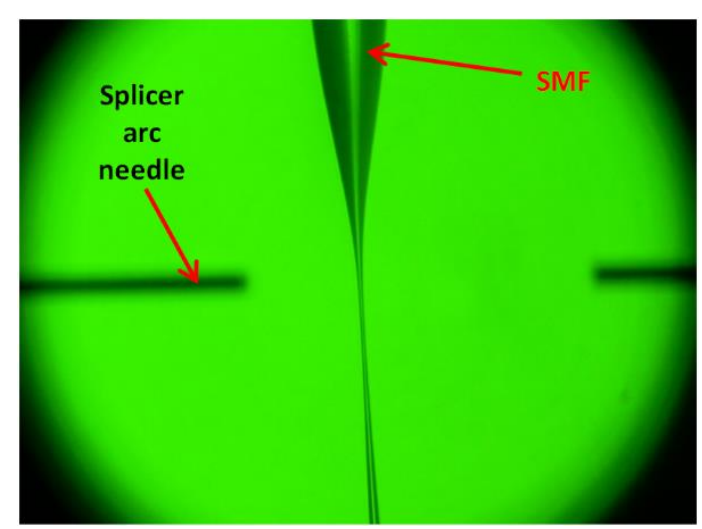

Fig. 2 Photograph of a tapered SMF formed by heating and pulling in a fusion splicer. Fiber waist diameter less than $10 \mu \mathrm{m}$ over a length of $300 \mu \mathrm{m}$.

\section{Optical Fiber Gratings}

A fiber Bragg grating (FBG) is a short section of fiber (usually a few millimeters length) where a grating has been written into a doped fiber core by creating periodic regions of high and low refractive index which is designed to reflect discrete wavelengths of light back along the core of the fiber. The index perturbations are caused by a photorefractive effect. A sub-group of gratings are known as long period gratings (LPGs) which couple the fundamental core mode to discrete, lossy, forward-propagating cladding modes and results in periodic wavelength-dependent dips in the transmission spectrum [9]. The cladding modes are confined by the cladding-external medium boundary. The wavelength selective loss is sensitive to changes in the refractive index of the external medium surrounding the fiber cladding, as the refractive index value modifies the phase-matched coupling conditions, and causes a shift in the position of the resonance dips. The advantage of a LPG based continuous fiber device is that the fiber does not need to be polished or tapered to access the light carried by the fiber; however the sensitivity of the light to the external medium is significantly reduced compared to a tapered fiber.

\section{FIBER GAP DEVICES}

A fiber-gap device is herein defined as either a single ended device (where light reflects from the end-face of a SMF) or an input/output pair of SMFs where light exits the input fiber, travels across a fiber gap which may contain a light modifying element and re-enters the output fiber. These non-continuous devices are prone to higher insertion losses than continuous fiber devices, but can be more robust than polished or tapered fibers. 


\section{A. Fiber Gap Devices: Microstructured Optical Fibers}

A special class of a fiber-gap device is the microstructured optical fiber (MOF) which is usually spliced to SMF at its input and output ends. A MOF is a fibre without the different core and cladding materials found in standard SMFs, but rather is a single silica fiber with a pattern of air holes (with diameters usually below $10 \mu \mathrm{m}$ ) running along the long axis of the fiber. The geometrical arrangement of air holes around the centre of the fiber creates the conditions which allows lightguiding in the fiber. Filling these air holes with a fluid yields the possibility of highly integrated fiber optofluidic devices with increased sensitivity and functionality, especially if the optical properties of the fluid can be modified externally. A fiber with a periodic arrangement of holes is often called photonic crystal fiber (PCF) [10]. If a fluid of refractive index higher than the core index fills the holes of the PCF it is classed as a photonic bandgap fiber (PBGF) with narrower passband regions in the optical transmission spectrum. In contrast to SPFs, the MOF retains its robustness, but filling the air holes with a liquid can be difficult, sometimes involving application of a vacuum. Other issues are the increased scattering loss from the fluid filled holes, the increased optical losses incurred during splicing or coupling the short MOF section to a standard SMF [11], and the overall cost of manufacturing the MOF.

\section{FLUIDS COMMONLY USED WITH FIBER OPTOFLUIDIC DEVICES}

Fluids, such as liquid crystals (LCs) and magnetic fluids (MFs), have been regularly used to create fiber optofluidic devices because their properties can be controlled and are readily reversible. A LC is a high index fluid whose optical properties can be altered by a change of temperature, application of an electric field, or illumination with light. However, the strong temperature dependence of the LC's refractive index does represent a stability issue when developing optical devices incorporating LCs. In recent years MFs have attracted interest in the development of new optical devices. The MF (or ferrofluid) is a stable dispersion of ferromagnetic nanoparticles within a water or oil carrier. This liquid-particle combination allows parameters such as refractive index, birefringence, and physical position to be varied in the presence of an applied magnetic field. In addition, the refractive index of this fluid can also be changed by varying the concentration of the nanoparticles [12]. MFs can be actuated with low voltages $(<10 \mathrm{~V})$ which facilitates achieving miniaturization. However, these fluids also have a relatively large thermo-optical coefficient $\left(10^{-4}\right.$ compared to $10^{-6}$ for standard optical materials like fused silica).

\section{FIBER OPTOFLUIDIC MAGNETIC FIELD SENSORS}

The wide diversity of applications of magnetometers (from submarine detection, geological surveying, to oil and mineral exploration) greatly benefits from the advantages of fiber optics, especially immunity to electromagnetic interference and transmission of measurement data over long distances. In general the measurement method for these devices uses either a wavelength shift of a spectral feature or a measured optical transmission loss at a fixed wavelength. Using optical spectral analysis, the sensitivity of this class of fiber device will be limited by the resolution of the optical spectrum analyzer (typically 10 to $100 \mathrm{pm}$ ).

\section{A. Continuous Fiber Optofluidic Magnetic Field sensors}

The optical fiber taper has been used in the development of fiber optofluidic magnetic field sensors. In $2012 \mathrm{Li}$ et al. [13] reported tapering down a fiber to a $4 \mu \mathrm{m}$ waist diameter which had the flexibility to be pulled into a circular knot of diameter $380 \mu \mathrm{m}$. Guided light upon reaching the twisted portion of the knot underwent coupling to a resonance wavelength which shifted with external MF index changes to demonstrate a linear sensor over a magnetic field 0 to $22 \mathrm{mT}$ (sensitivity 9.1 $\mathrm{pm} / \mathrm{mT}$ ). More recently Layeghi et al. [14] pulled nonadiabatic tapers with waist diameters below $10 \mu \mathrm{m}$ over straight lengths from 1 to $1.5 \mathrm{~cm}$ (Fig. 3). The core mode encountering the non-adiabatic taper partly coupled to cladding modes and then re-coupled into the core beyond the taper to create measurable interferometric fringes. These tapers were immersed into a MF and gave a linear response up to a magnetic field strength of $44 \mathrm{mT}$ with a sensitivity of 72 $\mathrm{pm} / \mathrm{mT}$. Increasing the length of the taper, decreasing its diameter or changing the refractive index of the water-based magnetic fluid could further enhance the sensitivity.

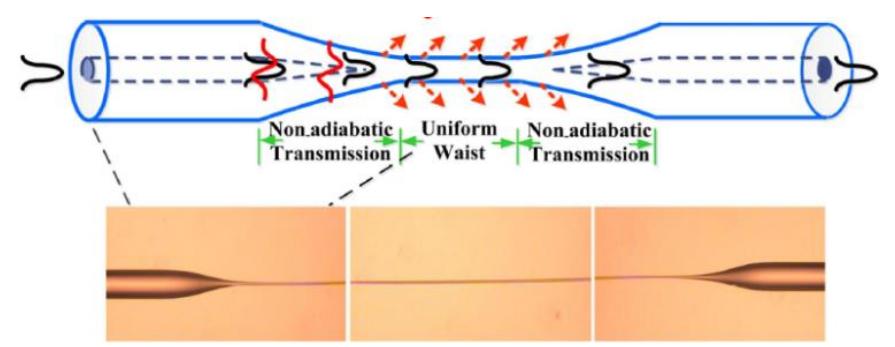

Fig. 3 Illustrating optical modes traversing a non-adiabatic tapered fiber and a photograph of this straight taper format (figure reproduced with permission from [14]).

Deng et al. [15] fabricated an asymmetric fiber taper of thicker waist diameter $(45 \mu \mathrm{m})$ in an S-shape format to create core and cladding modes that interferometrically recombine (Fig. 4). A thicker taper waist diameter can give the fiber an increased robustness compared to traditional taper formats with waist diameters below $10 \mu \mathrm{m}$. This fiber section was immersed in a MF and the optical intensity linearly decreased over the magnetic field range 0 to $185 \mathrm{mT}$. In addition, it was observed that for low magnetic field strengths up to $21 \mathrm{mT}$ the sensor demonstrated a higher sensitivity of approximately 162 $\mathrm{pm} / \mathrm{mT}$. 


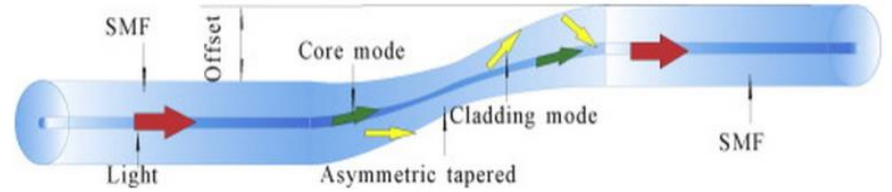

Fig. 4 Interferometric magnetic field sensor formed in a single S-shaped fiber (figure reproduced with permission from [15]).

Similarly, an S-shaped tapered fiber (taper waist diameter $65 \mu \mathrm{m})$ magnetometer was reported by Miao et al. [16] with a sensitivity of $560 \mathrm{pm} / \mathrm{mT}$, but the linear response range was relatively narrow (2.5 to $20 \mathrm{mT}$ ). Subsequently, the same authors investigated an alternative format by concatenating a $28 \mu \mathrm{m}$ diameter taper section with a core-offset fiber section (as illustrated in Fig. 5) to form a Mach-Zehnder interferometer system [17]. The core was offset by $20 \mu \mathrm{m}$ so that the interference only between the cladding modes was collected. Dong et al. [18] used this topology in the form of a taper of waist diameter $84 \mu \mathrm{m}$ followed by a fiber core offset of $14 \mu \mathrm{m}$ to fabricate a magnetic field sensor with two distinct linear regions. The first range was 3.8 to $25 \mathrm{mT}$ (with a sensitivity of $140 \mathrm{pm} / \mathrm{mT}$ ), above which the interference dip at wavelength $1583 \mathrm{~nm}$ disappeared as the increasing external refractive index caused leakage of the cladding modes, and was replaced by a second interference dip at $1557 \mathrm{~nm}$ which could be used as a linear sensor over a higher range of 25 to $47.5 \mathrm{mT}$ (sensitivity $260 \mathrm{pm} / \mathrm{mT}$ ).

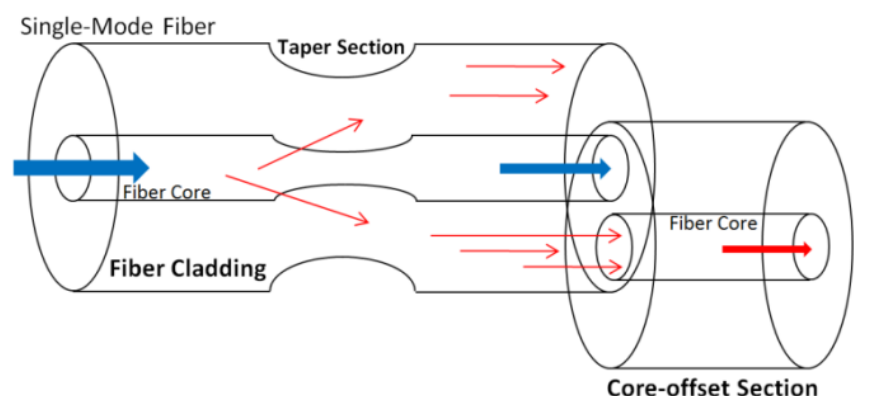

Fig. 5 Schematic of a fiber taper concatenated with a core offset section to collect cladding modes interference only (redrawn from [17] with permissions).

In an alternative approach, the same authors enlarged the diameter of a SMF ("uptapered") to $195 \mu \mathrm{m}$ at two points with a sensing region of length $14 \mathrm{~mm}$ between these points [19]. At the first modified point both the cladding and the core are enlarged which caused the core mode to expand and generate cladding modes that travel along the fiber (Fig. 6). At the second modified point the cladding modes interfere with the core mode and the optical signal is carried by the fiber core, with no lateral offset collection fiber used in this case. The formed sensor was immersed in a MF and demonstrated a wavelength shift over the range of 0 to $16 \mathrm{mT}$ with a sensitivity up to $325 \mathrm{pm} / \mathrm{mT}$.

Table I summarizes the continuous fiber optofluidic magnetometers demonstrated to date together with their range of linear operation and sensitivity achieved.

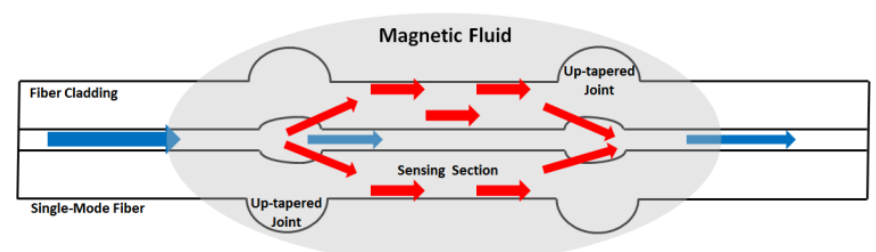

Fig. 6 Fiber optofluidic magnetometer based on two"up-tapered" fiber regions forming a sensing section that is immersed into a MF (redrawn from [19]).

TABLE I

CONTINUOUS FIBER OPTOFLUIDIC MAGNETOMETERS

\begin{tabular}{|c|c|c|c|c|}
\hline Author & $\begin{array}{c}\text { Device } \\
\text { Format }\end{array}$ & $\begin{array}{c}\text { Nanoparticles } \\
\text { in MF } \\
\text { (vol. \%) }\end{array}$ & $\begin{array}{c}\text { Linear } \\
\text { Range } \\
(\mathbf{m T})\end{array}$ & $\begin{array}{c}\text { Sensitivity } \\
(\mathbf{p m} / \mathbf{m T})\end{array}$ \\
\hline $\begin{array}{c}\text { Miao et al. } \\
{[16]}\end{array}$ & $\begin{array}{l}\text { S-shaped } \\
\text { taper }\end{array}$ & 3.9 & 2.5 to 20 & 560 \\
\hline $\begin{array}{c}\text { Pu et al. } \\
\text { [19] }\end{array}$ & Up taper & 1.9 & 0 to 16 & 325 \\
\hline $\begin{array}{c}\text { Deng et al. } \\
{[15]}\end{array}$ & $\begin{array}{l}\text { S-shaped } \\
\text { taper }\end{array}$ & 3.5 & 0 to 21 & 162 \\
\hline $\begin{array}{c}\text { Dong et al. } \\
{[18]}\end{array}$ & $\begin{array}{c}\text { Taper } \\
\text { followed } \\
\text { by } \\
\text { core offset }\end{array}$ & 1.9 & $\begin{array}{l}3.8 \text { to } 25 \\
25 \text { to } 47\end{array}$ & $\begin{array}{l}140 \\
260\end{array}$ \\
\hline $\begin{array}{c}\text { Layeghi et } \\
\text { al. [14] }\end{array}$ & $\begin{array}{c}\text { Straight } \\
\text { taper }\end{array}$ & 0.1 & 0 to 44 & 72 \\
\hline $\begin{array}{c}\text { Li et al. } \\
\text { [13] }\end{array}$ & $\begin{array}{l}\text { Taper with } \\
\text { microKnot }\end{array}$ & 2.0 & 0 to 22 & 9.1 \\
\hline
\end{tabular}

\section{B. Fiber-Gap Optofluidic Magnetic Field Sensors}

In $2012 \mathrm{Zu}$ et al. [20] used a Sagnac interferometer incorporating a $50 \mathrm{~cm}$ section of polarization maintaining (PM) fiber to form a magnetic field sensor. A birefringent MF film placed perpendicularly in the optical path between two SMFs introduced a phase difference and differential absorption to the ordinary and extraordinary optical rays. This system produced an optical wavelength shift of the interference spectrum of $167 \mathrm{pm} / \mathrm{mT}$ for field strengths up to $40 \mathrm{mT}$. These researchers adapted their system to include two high birefringence fibers to demonstrate a magnetic field sensor with a much higher sensitivity of $5930 \mathrm{pm} / \mathrm{mT}$ [21]. Wang et al. [22] spliced a $12 \mathrm{~mm}$ section of etched multimode fiber MMF (core diameter $105 \mu \mathrm{m}$ ) between two SMFs and then etched the MMF cladding diameter down to $112 \mu \mathrm{m}$. The finished sensor was immersed in a MF and gave a wavelength shift sensitivity of $1686 \mathrm{pm} / \mathrm{mT}$ over the magnetic field range of 12 to $32.5 \mathrm{mT}$.

Lin et al. [23] fabricated a multimode interferometer by splicing standard SMFs to both ends of a $9 \mathrm{~mm}$ long square cross-section $(90 \mu \mathrm{m} \times 90 \mu \mathrm{m})$ no-core fiber $(\mathrm{NCF})$ and immersed this section in a MF. The interference spectrum of the high order optical modes within the NCF was sensitive to external refractive index changes induced by a magnetic field. A linear sensor response in transmission mode occurred over the range 10 to $25 \mathrm{mT}$. Subsequently, these researchers experimented with a similar $30 \mathrm{~mm}$ long square NCF tapered down to a $40 \mu \mathrm{m}$ waist diameter over a length of $390 \mu \mathrm{m}$ [24]. This sensor over the range 2.5 to $27 \mathrm{mT}$ demonstrated a sensitivity of $187 \mathrm{pm} / \mathrm{mT}$. In 2013 Chen et al. [25] achieved a sensitivity of $905 \mathrm{pm} / \mathrm{mT}$ using a $61.5 \mu \mathrm{m}$ diameter untapered 
$9.4 \mathrm{~cm}$ long NCF. However, the region of sensor linearity was limited to the range 4 to $10 \mathrm{mT}$ and the insertion loss was 9.7 $\mathrm{dB}$ at a wavelength of $1560 \mathrm{~nm}$. In the following year these researchers expanded on this work by performing a comparative study of a straight and U-shaped NCF between two SMFs [26]. By bending the NCF to increase the penetration depth of the evanescent field they increased the sensitivity to $3185 \mathrm{pm} / \mathrm{mT}$, which was over 4 times the sensitivity of a straight NCF sensor.

Gao et al. [27] increased the sensitivity of a LPG based MF magnetometer by writing the LPG into a D-shaped fiber section spliced between two SMFs. The sensitivity was moderate at $176 \mathrm{pm} / \mathrm{mT}$, but the linear range was extended to 0 to $100 \mathrm{mT}$. Deng et al. [28] combined a MF with a Michelson interferometer in a compact fiber based format. A $\mathrm{CO}_{2}$ laser cut an ellipsoidal groove into a SMF to a depth of $60 \mu \mathrm{m}$ near the distal end far end of a SMF (Fig. 7). An optical core mode reaching this notch will enlarge and generate cladding modes that propagate beyond the notch over a short length to the cleaved fiber end where they undergo reflection. The core and cladding modes recombine at the notch to produce interference fringes. The fiber section between the notch and the cleaved end was immersed into a MF and the evanescent field of the cladding modes interacted with the MF whilst the light in the core was not influenced by a changing magnetic field. This sensor operated over the longer linear range of 0 to $107 \mathrm{mT}$, but with a low sensitivity of $3.2 \mathrm{pm} / \mathrm{mT}$. It was speculated that a low-order cladding mode was being preferentially excited and therefore to increase the evanescent field penetration the authors etched the sensing section diameter down to $50 \mu \mathrm{m}$ and thus increased the sensitivity to $65 \mathrm{pm} / \mathrm{mT}$.

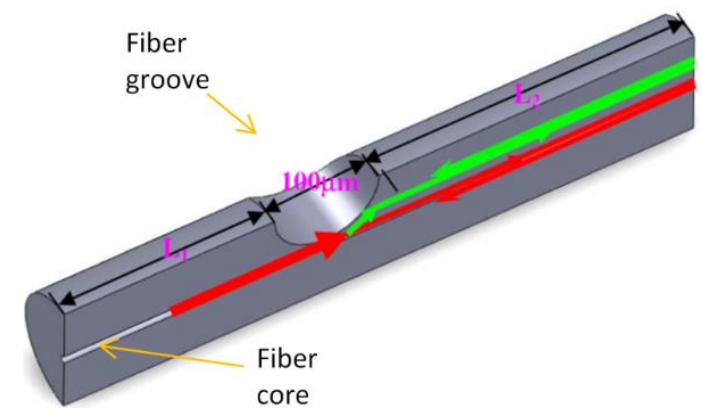

Fig. 7 Illustration of a Michelson interferometer formed in the distal end of a SMF by reducing the fiber cladding over a length of $100 \mu \mathrm{m}$ (figure reproduced with permission from [28]).

A compact single-ended fiber optic magnetic field probe developed by Dong et al. [29] consisted of an air-gap cavity formed between the end of a cleaved fiber and an oil-based MF column (Fig. 8). Reflections occurred from each end of the cavity resulting in optical interference and a wavelength passband developed depending on parameters such as cavity length. By applying a varying external magnetic field the length of the MF column and thus the cavity length would change causing a measureable shift of the interference spectrum with a sensitivity of $117 \mathrm{pm} / \mathrm{mT}$. However, due to the sensitivity of this fiber Farby-Perot (FP) interferometer to temperature variations the sensor head was sealed in a secondary water vessel and maintained at $22^{\circ} \mathrm{C}$.

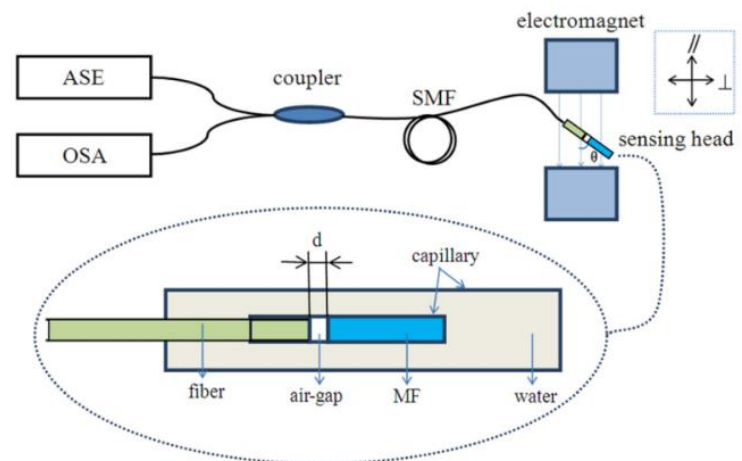

Fig. 8 Schematic of a magnetometer using a variable length air gap cavity (figure reproduced with permission from [29]).

In a similar format Lv et al. [30] created a magnetic sensor probe head consisting of two SMFs with a MF-filled cavity between them. As the refractive index of the MF varied the phase of the light in the cavity changed and shifted the measured optical spectrum. Over the range 0 to $40 \mathrm{mT}$ the sensor showed a linear response with a measurement sensitivity of $431 \mathrm{pm} / \mathrm{mT}$. The application of strong magnetic fields was accompanied by a rise in temperature which affected the refractive index of the MF. Therefore these researchers subsequently incorporated a FBG in front of their FP cavity (Fig. 9) to allow temperature compensation by monitoring the shift of Bragg wavelength with temperature [31]. The sensor showed good linearity up to $60 \mathrm{mT}$ with a sensitivity of $400 \mathrm{pm} / \mathrm{mT}$.

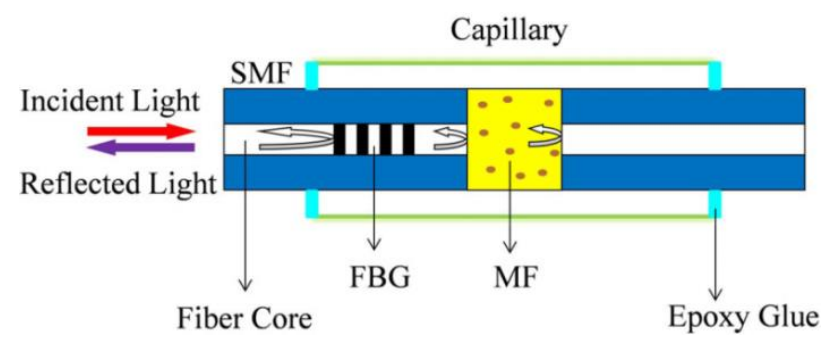

Fig. 9 Farby-Perot magnetometer incorporating a FBG for temperature compensation (figure reproduced with permission from [31]).

The fiber optofluidic sensors described above have generally employed non-standard (i.e. specially fabricated or modified) optical fibers such as tapers, FBGs, notched SMF, or SMF-MMF-SMF combinations. However, Homa and Pickrell [32] demonstrated that using off-the-shelf components with the correct choice of MF can produce a magnetic sensor with a high sensitivity. Their magnetometer consisted of a pair of flat faced FC/PC optical fiber connectors housed within a standard mating sleeve with a MF filling the gap between the fiber end-faces to form a FP interferometer. Only $10 \mu \mathrm{L}$ of fluid was required in this device. Two oil-based MFs were tested with particle concentrations of $8 \%$ and $18 \%$. The $8 \%$ MFs yielded a moderate sensitivity of $326 \mathrm{pm} / \mathrm{mT}$ whilst the more concentrated $18 \%$ demonstrated a high sensitivity of $2300 \mathrm{pm} / \mathrm{mT}$, which was close to that achieved by Zhang et al. 
[26] using a U-shaped NCF. However, the range of linear response of this simple magnetic field sensor was found to be limited to the range of 3 to $7 \mathrm{mT}$. The range of sensitivities achieved by fiber-gap optofluidic magnetometers are listed in Table II together with their varied linear operating ranges.

TABLE II

FIBER GAP FIBER OPTOFLUIDIC MAGNETOMETERS

\begin{tabular}{|c|c|c|c|c|}
\hline Authors & $\begin{array}{l}\text { Device } \\
\text { Format }\end{array}$ & $\begin{array}{c}\text { Nanoparticles } \\
\text { in MF } \\
(\text { vol. \%) }\end{array}$ & $\begin{array}{c}\text { Linear } \\
\text { Range } \\
(\mathbf{m T})\end{array}$ & $\begin{array}{c}\text { Sensitivity } \\
(\mathrm{pm} / \mathrm{mT})\end{array}$ \\
\hline $\begin{array}{c}\text { Zu et al. } \\
\text { [21] }\end{array}$ & $\begin{array}{c}\text { Sagnac } \\
\text { interferometer }\end{array}$ & 3.9 & 0 to 50 & 5,930 \\
\hline $\begin{array}{c}\text { Zhang et al. } \\
{[26]}\end{array}$ & $\begin{array}{l}\text { U-shaped } \\
\text { NCF }\end{array}$ & 3.9 & 1.6 to 9.6 & 3,185 \\
\hline $\begin{array}{c}\text { Homa and } \\
\text { Pickrell } \\
{[32]}\end{array}$ & $\begin{array}{c}\text { Fabry-Perot } \\
\text { interferometer }\end{array}$ & $\begin{array}{l}17.7 \\
7.9\end{array}$ & $\begin{array}{l}3 \text { to } 7 \\
6 \text { to } 13\end{array}$ & $\begin{array}{c}2,300 \\
326\end{array}$ \\
\hline $\begin{array}{c}\text { Wang et al. } \\
\text { [22] }\end{array}$ & Etched MMF & 1.9 & 12 to 32 & 1,686 \\
\hline $\begin{array}{c}\text { Chen et al. } \\
{[25]}\end{array}$ & $\mathrm{NCF}$ & 3.9 & 4 to 10 & 905 \\
\hline $\begin{array}{c}\text { Lv et al. } \\
\text { [30] }\end{array}$ & $\begin{array}{c}\text { Fabry-Pérot } \\
\text { interferometer }\end{array}$ & 2.0 & 0 to 40 & 431 \\
\hline $\begin{array}{c}\text { Zhao et al. } \\
\text { [31] }\end{array}$ & $\begin{array}{c}\text { Farby-Perot } \\
\text { concatenated } \\
\text { with FBG }\end{array}$ & 1.8 & 0 to 60 & 400 \\
\hline $\begin{array}{l}\text { Miao et al. } \\
{[24]}\end{array}$ & Tapered NCF & 3.9 & 2.5 to 27 & 187 \\
\hline $\begin{array}{l}\text { Gao et al. } \\
\text { [27] }\end{array}$ & $\begin{array}{l}\text { LPG within } \\
\text { D-fiber }\end{array}$ & 3.9 & 0 to 100 & 176 \\
\hline $\begin{array}{c}\text { Zu et al. } \\
{[20]}\end{array}$ & $\begin{array}{c}\text { Sagnac } \\
\text { interferometer }\end{array}$ & 3.9 & 0 to 40 & 167 \\
\hline $\begin{array}{c}\text { Dong et al. } \\
{[29]}\end{array}$ & $\begin{array}{c}\text { Fabry-Pérot } \\
\text { interferometer }\end{array}$ & 5.6 & 0 to 30 & 117 \\
\hline $\begin{array}{c}\text { Deng et al. } \\
{[28]}\end{array}$ & $\begin{array}{c}\text { Michelson } \\
\text { interferometer }\end{array}$ & 3.5 & 0 to 107 & 65 \\
\hline
\end{tabular}

\section{MOF Optofluidic Magnetic Field Sensors}

A standard SMF has higher temperature sensitivity than a MOF since the different materials constituting the core and cladding will have different thermal expansion coefficients. In $2012 \mathrm{Zu}$ et al. [33] did not infiltrate a PCF with a fluid but kept the air-filled holes to demonstrate the temperaturedependent coefficient of their PCF-based magnetic field sensor was 3 orders of magnitude better than a standard SMF. The sensor (immersed in a MF) had a relatively low sensitivity of $24 \mathrm{pm} / \mathrm{mT}$. Subsequently, these researchers experimented with raising the refractive index of a MF by solvating the ferromagnetic nanoparticles in toluene (refractive index 1.497) and introduced this fluid into the holes of a $20 \mathrm{~mm}$ section of a PCF to transform it into a PBGF spliced between SMFs [34]. The series of transmission bands in the optical spectrum was monitored as an external magnetic field was varied. A linear band shift was observed for field strengths up to $3 \mathrm{mT}$ with a much higher sensitivity of $15,600 \mathrm{pm} / \mathrm{mT}$, much greater than other reported optical fiber magnetic field sensors (albeit over a very limited range). However, the device also had an insertion loss of about $6 \mathrm{~dB}$. Miao et al. [35] fabricated a LPG within a PCF and filled the holes with a MF which had a relatively high $7.1 \%$ particle volume concentration. The PCF was spliced between two SMFs. The resonance wavelength of the LPG is dependent on the refractive index difference of the core and cladding modes which can be used to sense index changes in the MF induced by an external magnetic field. Over a larger magnetic field range 0 to $30 \mathrm{mT}$ the sensor provided a linear response with an even higher sensitivity of $19,460 \mathrm{pm} / \mathrm{mT}$.

Thakur et al. [36] extended the linear range up to $45 \mathrm{mT}$ using birefringence change in a polarization maintaining PCF infiltrated with MF, but with a more limited sensitivity of 242 $\mathrm{pm} / \mathrm{mT}$. Gao et al. [37] infiltrated a water-based MF into the air holes around a $10.4 \mathrm{~cm}$ long solid core PCF to demonstrate a magnetic field sensor using simple transmission loss measurements. Upon application of an increasing magnetic field, the refractive index of the fluid rises and index guiding is reduced and the optical transmission falls. The sensor showed a linear response over the range of 20 to $60 \mathrm{mT}$.

Researchers have also experimented with tapered and hollow core PCFs. Zhao et al. [38] tapered a PCF to a diameter of $24 \mu \mathrm{m}$ and length $804 \mu \mathrm{m}$ (Fig. 10) and this section was immersed in a MF to which a changing magnetic field intensity (10 to $60 \mathrm{mT})$ was applied. The sensitivity of this magnetic field sensor was moderate at approximately 160 $\mathrm{pm} / \mathrm{mT}$.

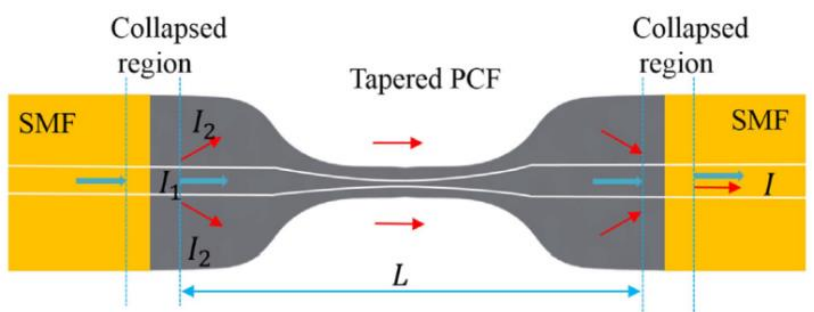

Fig. 10 Mach Zehnder interferometer formed in a tapered PCF (figure reproduced with permission from [38]).

In a single ended configuration, a MF-filled $40 \mu \mathrm{m}$ diameter hollow core PCF formed the basis of a FP interferometer [39] with a cavity length of $200 \mu \mathrm{m}$. On the input end of the PCF a partially reflecting/transmitting $\mathrm{Ti}_{2} \mathrm{O}_{3}$ film was placed and at the other end a fully reflecting film (Fig. 11). By applying a varying external magnetic field the refractive index of the fluid filled core changed which caused the location of resonance peaks of the output spectrum to change accordingly. This FP-based sensor demonstrated a linear response over the magnetic field range 5 to $17 \mathrm{mT}$ with a sensitivity of 330 $\mathrm{pm} / \mathrm{mT}$.

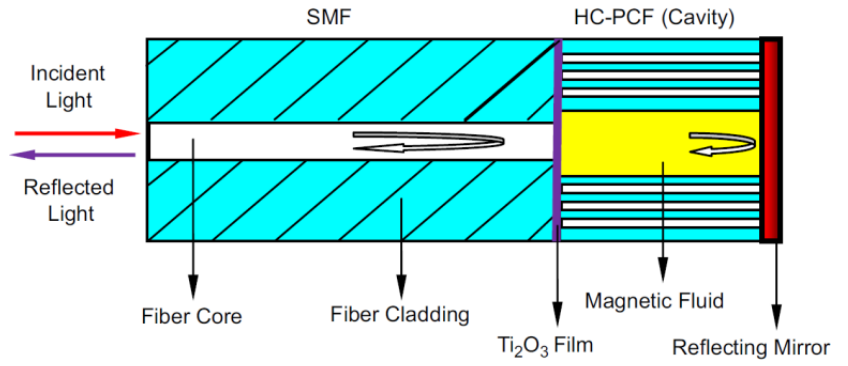

Fig. 11 SMF addressing a Farby-Perot cavity incorporating a magnetic fluid for magnetic field measurements (figure reproduced with permission from [39]). 
Table III summarizes the sensitivities and operating ranges of the small number of PCF optofluidic magnetometers reported to date demonstrating a limited range but able to achieve very high sensitivities. In comparison, fiber optic magnetometers employing coatings of TerfenolD films [40] and magnetostrictive TbDyFe coatings [41] have a reported sensitivity around $1 \mathrm{pm} / \mathrm{mT}$.

TABLE III

PCF OPTOFLUIDIC MAGNETOMETERS

\begin{tabular}{|c|c|c|c|c|}
\hline Authors & $\begin{array}{c}\text { Device } \\
\text { Format }\end{array}$ & $\begin{array}{c}\text { Nanoparticles } \\
\text { in MF } \\
\text { (vol. \%) }\end{array}$ & $\begin{array}{c}\text { Linear } \\
\text { Range } \\
\text { (mT) }\end{array}$ & $\begin{array}{c}\text { Sensitivity } \\
\text { (pm/mT) }\end{array}$ \\
\hline $\begin{array}{c}\text { Miao et } \\
\text { al. } \\
\text { [35] }\end{array}$ & $\begin{array}{c}\text { LPG-PCF } \\
\text { infiltrated } \\
\text { with MF }\end{array}$ & 7.1 & 0 to 30 & 19,460 \\
\hline $\begin{array}{c}\text { P. Zu et } \\
\text { al. [34] }\end{array}$ & $\begin{array}{c}\text { PBGF } \\
\text { infiltrated } \\
\text { with MF }\end{array}$ & 2.5 & 0 to 3 & 15,600 \\
\hline $\begin{array}{c}\text { Zhao et } \\
\text { al. [39] }\end{array}$ & $\begin{array}{c}\text { MF in hollow } \\
\text { core PCF }\end{array}$ & & 5 to 17 & 330 \\
\hline $\begin{array}{c}\text { Thakur et } \\
\text { al. [36] }\end{array}$ & PM-PCF & 1.8 & 10 to 60 & 160 \\
\hline $\begin{array}{c}\text { Zhao et } \\
\text { al. [38] }\end{array}$ & Tapered PCF & 0.4 & 0 to 30 & 24 \\
\hline $\begin{array}{c}\text { P. Zu et } \\
\text { al. [33] }\end{array}$ & Standard PCF & & \\
\hline
\end{tabular}

\section{FIBER OPTOFLUIDIC ELECTRIC FIELD SENSOR}

A fiber optofluidic device can form an electric field sensor that, unlike traditional sensors, will minimally perturb the field being measured and whose transmitted optical signals relayed from the sensor can be free from electromagnetic interference.

\section{A. MOF Optofluidic Electric Field Sensor}

The close integration of a LC with the optical signal within a PCF lends itself to simpler designs and smaller size compared to electric field sensors employing electro-optical crystals and using bulk or free space optics. Mathews et al. [42] demonstrated an electric field sensor based on a LC within a PCF that operated in either transmission or in reflection mode (to form an end-point sensor). The LC infiltrated section with an increasing applied electric field (above a threshold of $2.35 \mathrm{kV}_{\mathrm{rms}} / \mathrm{mm}$ ) re-orientated the $\mathrm{LC}$ molecules to increase the effective refractive index and decreased the optical transmission at $1550 \mathrm{~nm}$. The sensor was linear over the range 2.35 up to $5.14 \mathrm{kV}_{\mathrm{rms}} / \mathrm{mm}$ in reflection mode. The authors suggested the electric field threshold could be lowered by increasing the diameter of the holes in the PCF or a LC that is less initially aligned with the fiber axis.

\section{FIBER OPTOFLUIDIC OPTICAL ATTENUATORS}

SMF optical attenuators are widely used in fiber optical communications to dynamically control the optical power level from light sources, the gain equalization of amplifiers, and to manage the optical power in receiver front-ends to avoid optical overload [43]. In the field of optical test and measurement, attenuators are used to evaluate photoreceivers for dynamic range and linearity, and for avoiding saturation of optical detectors during optical sensitivity measurements. Progress towards miniaturization of attenuators has been facilitated by micro-electro-mechanical system (MEMS) implementations of fiber optical attenuators, but MEMS devices can have reliability issues associated with the movable micromechanical parts [44]. Alternatively, optofluidics can be used to form attenuators with no mechanical moving parts. Desired minimum characteristics of practical attenuators are a variable optical attenuation range of at least $20 \mathrm{~dB}$ and broadband operation.

\section{A. Continuous Fiber Optofluidic VOAs}

In 2003 J. Hsieh et al. demonstrated an early example of a continuous fiber optofluidic VOA by combining a LPG with a sodium dichromate-water solution to demonstrate a narrowband VOA at $1538 \mathrm{~nm}$ with a dynamic range of $20 \mathrm{~dB}$ [45]. However, sodium dichromate is a highly toxic substance, hence alternative fluids are needed. These researchers subsequently extended the bandwidth to over $40 \mathrm{~nm}$ in conjunction with a fluid of water and ionic salt [46]. Gu et al. [47] placed a LC between the transparent conductive material indium tin oxide (ITO) located upon a SPF. By applying a variable voltage to the ITO the refractive index of the LC was changed, modifying the optical transmission loss through the fiber. The maximum broadband attenuation achieved was approximately $25 \mathrm{~dB}$ for $20 \mathrm{~V}$ applied with only $0.2 \mathrm{~dB}$ insertion loss.

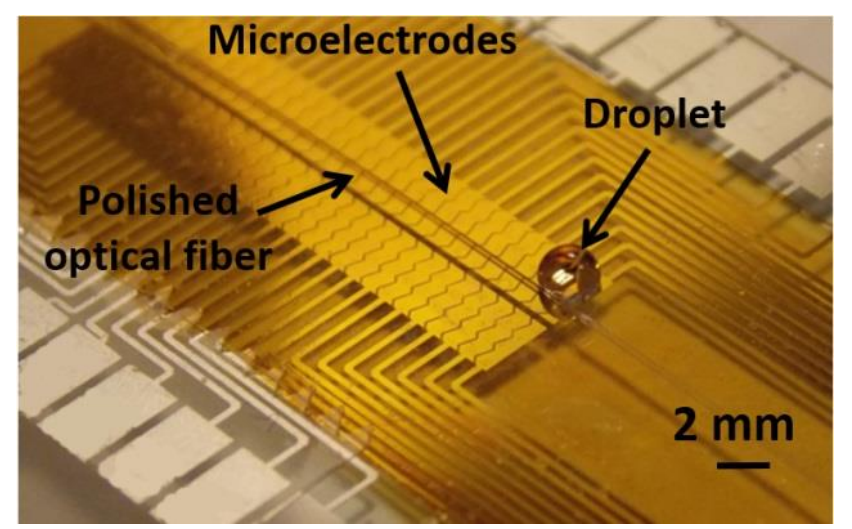

Fig. 12 Electrowetting platform used to translate liquid droplets along the polished face of a SMF to create an in-line VOA.

More recently, Duduś et al. [48] reported a broadband VOA employing a SPF integrated on an electrowetting-on-dielectric platform to demonstrate $26 \mathrm{~dB}$ of attenuation. The system was designed to translate miniature droplets of water-glycerine solution along the SPF by applying a voltage (typically $180 \mathrm{~V}$ ) to the platform (Fig. 12). The polished section had a tapering cladding profile that reached a minimum thickness at the center of the polished region. The refractive index of the droplet matched that of the fiber core which allowed 
increasing radiative loss through the optical evanescent field as the liquid droplet translated along the polished section, progressively getting closer to the fiber core. It was found that the size and the refractive index of the droplet together with the topology of the polished cladding were important parameters that strongly influenced the attenuator performance. In addition, to be viable such a device will require to be environmentally sealed to minimize evaporation of the droplets [49].

\section{B. Fiber-Gap Optofluidic VOAs}

Hongbin et al. [50] reported a fiber gap optofluidic VOA which was based on an opaque liquid situated in a cavity between two optical fibers. Pumping air into a cavity deformed a membrane that in turn displaced the absorbing liquid from the optical transmission path. This simple system was fabricated using standard processing of low cost materials polydimethylsiloxane (PDMS) and SU-8 photoresist and achieved an optical dynamic range of $38 \mathrm{~dB}$ with only $0.48 \mathrm{~dB}$ insertion loss.

Lapsley et al. [51] demonstrated an optofluidic VOA based on variable interfacial reflection from a water-based microfluidic channel between two fibers and achieved an optical broadband attenuation up to $35 \mathrm{~dB}$. Two reservoirs containing either water or a $\mathrm{CaCl}_{2}$ solution fed into a common PDMS microchannel (Fig. 13). By varying the concentration of $\mathrm{CaCl}_{2}$ the refractive index of the solution could be controlled so as to alter the reflectivity of the liquid/PDMS surface and thus the light reflected between the fibers. A disadvantage of this system is that the fluidic system is an open loop system which means the fluid once used cannot be used again and depletes the reservoir. Additionally, for the device to operate required syringe pump systems to inject the liquids to channel thereby increasing the size of the final device setup.

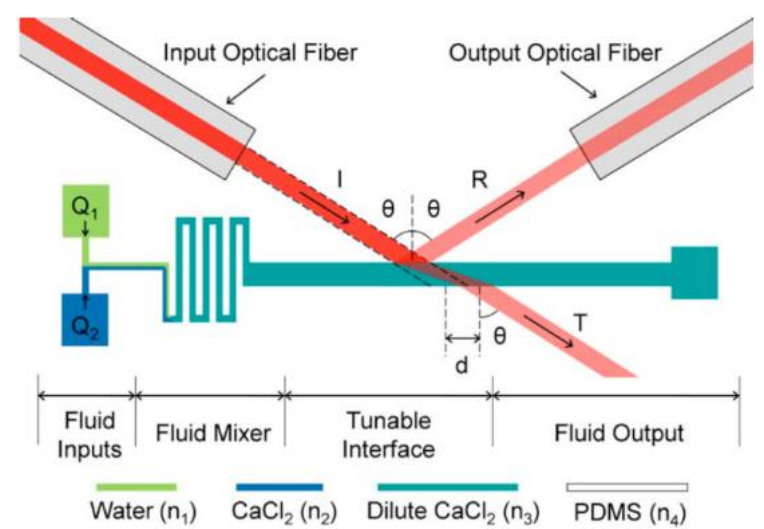

Fig. 13 Fiber optofluidic attenuator using controlled reflection from a fluidic channel interface (figure reproduced with permission from [51]).

Reza et al. used an electrowetting actuated liquid lens to control optical power coupling between SMFs and created a VOA with up to $40 \mathrm{~dB}$ range [52]. Subsequently, they integrated a micromirror with their liquid lens to increase the broadband dynamic range to over $63 \mathrm{~dB}$ with a $100 \mathrm{~ms}$ switching time [53]. However, the overall insertion loss was close to $5 \mathrm{~dB}$ in this case. Similarly, a voltage induced dielectric force was used to stretch a LC across an aperture between lensed SMFs to increasingly deflect the light achieving a VOA with a range of $32 \mathrm{~dB}$ (insertion loss of 0.7 $\mathrm{dB}$ ) and response time approximately $20 \mathrm{~ms}$ [54]. More recently, Duduś et al. [55] reported an "all-fluidic" shuttertype VOA employing a MF actuator/shutter combination located between two lensed-SMFs (Fig. 14). The fluid shutter (consisting of an oil-based MF and a glycerine-water solution) was translated by a miniature electromagnet to produce an optical attenuation of $28 \mathrm{~dB}$. The attenuation was limited by the concentration of the ferrofluid that did not leave a residue on the channel glass wall and thus affect the reversibility. In comparison to other VOAs, this broadband optofluidic VOA was of simple design and had relatively low operating voltage $(4 \mathrm{~V})$, and achieved an optical attenuation range which meets typical application requirements. However, the $100 \%$ on/off response time was up to 3 secs.

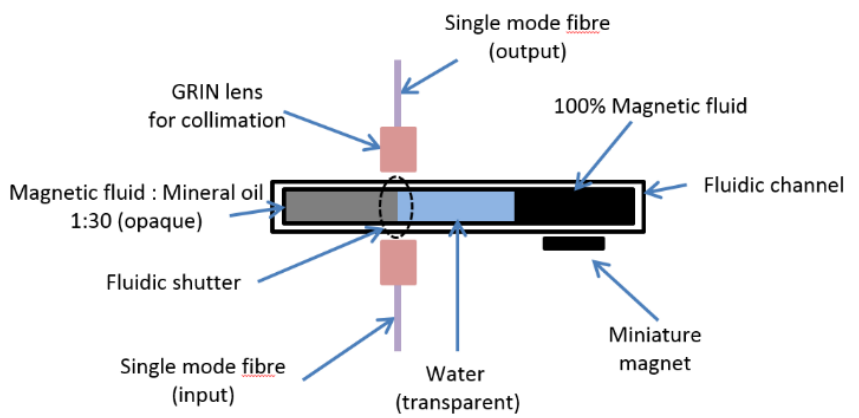

Fig. 14 Schematic of a SMF VOA using a magnetic fluid shutter whose position can be controlled by application of a magnetic field.

\section{MOF Optofluidic VOAs}

In an early demonstration of the possibilities of combining liquids and MOFs, Kerbage et al. [56] tapered a MOF from 125 to 30 microns (Fig. 15) causing the optical core mode to spread into the air holes in the cladding [57]. A liquid polymer of refractive index of 1.424 was positioned in the taper region and subsequent heating of the fibre reversibly changed the index of the polymer to create a variable attenuator with a 29 $\mathrm{dB}$ range and low insertion loss of $0.8 \mathrm{~dB}$. By using a higher index fluid (methylene iodide, index $\sim 1.78$ ) a variable attenuation of $45 \mathrm{~dB}$ was also demonstrated by modulating a microheater on the fibre to change the pressure within the sealed air holes and push the fluid into and out of the tapered region [58].

Mathews et al. [59] used their LC filled PCF technology to demonstrate an electrically controlled linear VOA with an attenuation range of $40 \mathrm{~dB}$ for an applied voltage from 170 to 310 volts and a response time of less than $20 \mathrm{msec}$, together with a flat spectral response across the 1500 to $1600 \mathrm{~nm}$ wavelength region.

The range of attenuations achieved by these fiber optofluidic VOAs are summarized in Table IV together with the device format. 


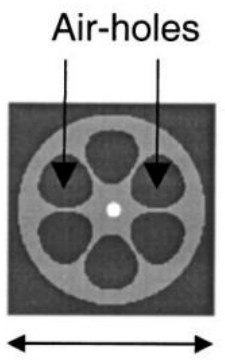

$125 \mu \mathrm{m}$

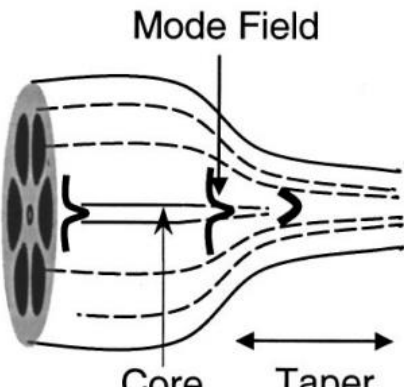

Taper

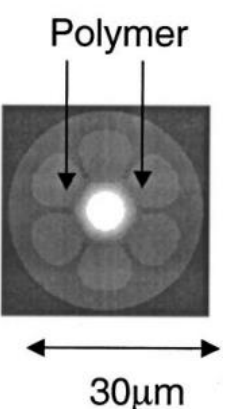

Fig. 15 Tapering of a MOF increases modal field penetration into surrounding air holes containing an infused liquid polymer (figure reproduced with permission from [56]).

TABLE IV

FIBER OPTOFLUIDIC VOAS

\begin{tabular}{|c|c|c|}
\hline Authors & Device Format & $\begin{array}{c}\text { Linear Attenuation } \\
\text { range (dB) }\end{array}$ \\
\hline Reza et al. [53] & Liquid lens plus mirror & 63 \\
\hline Reza et al. [52] & Liquid lens & 40 \\
\hline Kerbage et al. [58] & Liquid filled MOF & 45 \\
\hline Mathews et al. [59] & LC filled PCF & 40 \\
\hline Hongbin et al. [50] & $\begin{array}{c}\text { Air pumped opaque } \\
\text { liquid between two fibers }\end{array}$ & 38 \\
\hline Lapsley et al. [51] & $\begin{array}{c}\text { Differential index } \\
\text { reflection }\end{array}$ & 35 \\
\hline Xu et al. [54] & Stretching LC & 32 \\
\hline Kerbage et al. [56] & Polymer filled MOF & 29 \\
\hline Duduś et al. [55] & Ferrofluid shutter & 28 \\
\hline Duduś et al. [49] & SPF with water-glycerine & 26 \\
\hline Gu et al. [47] & SPF and LC & 25 \\
\hline Acharya et al. [46] & LPG with water-salt & 20 \\
\hline & & \\
\hline
\end{tabular}

\section{FIBER OPTOFLUIDIC OPTICAL SWITCHES AND FILTERS}

Fiber optic switches and filters are used for controlling signals in optical networks to protect equipment as well as adding and dropping signals. Switches have been based on MEMS actuated mirrors [60], electro-optic and thermo-optic effects in materials to switch light between output ports [61, 62], rotation of light polarization by voltages applied to LCs [63], and acousto-optic effects to form variable gratings in materials to re-direct light [64]. Tunable optical filters are highly desirable since they have the flexibility to change the wavelengths they pass or reject. Each of these has their advantages and disadvantages and the creation of new switches and filters is an area of ongoing research. There have been demonstrations of several types of optofluidic switches and filters.

\section{A. Continuous Fiber Optofluidic Switches and Filters}

$\mathrm{Gu}$ et al. [47] proposed an in-line wavelength-selective $2 \times 2$ switch where a grating (consisting of the photopolymer and the LC sections) was situated between two side-polished fibers with ITO coatings (Fig. 16). Upon application of a voltage the refractive index of the LC was tuned to be the same as the polymer, thus removing the grating structure. These on-off states allow wavelengths to be added or dropped from each fiber. $\mathrm{Yu}$ et al. [65] adapted their photoresponsive LC technology to create short and long period gratings within a LC above a SPF. By changing the intensity of the irradiating laser light the resonant wavelengths in the transmission spectra through the fiber could be tuned up to $60 \mathrm{~nm}$.

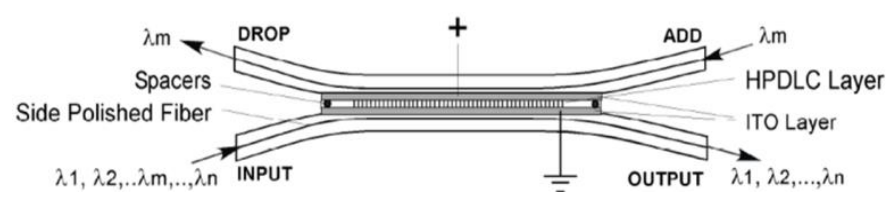

Fig. 16 SMF wavelength switching using a $2 \times 2$ switch incorporating a combined liquid crystal and photopolymer (figure reproduced with permission from [46]).

\section{B. Fiber-Gap-Optofluidic Switches}

In 1998 Fouquet et al. [66] reported a novel 4x4 optical switch that used thermally-generated bubbles to switch the light between fibers with an extinction ratio up to $70 \mathrm{~dB}$ which outperformed other switches. Nanoparticles within a MF in the presence of strong laser light will form clusters and this was used by Dai et al. [67] to demonstrate all-optical switching by increasing the scattering of light of wavelength $1550 \mathrm{~nm}$ travelling between two SMFs, with an extinction ratio close to $40 \mathrm{~dB}$. However, the optical power of the controlling light was high - $350 \mathrm{~mW}$ - for full on and off recovery cycle. Brandhoff et al. [68] reported a novel optofluidic device that switched light from an input to four output fibers using an aqueous$\mathrm{CaCl}_{2}$ droplet moving along a fluidic channel. The researchers successfully demonstrated switching light out of the channel at specific points with a measured on:off ratio of up to 20:1.

\section{MOF Optofluidic Switches and Filters}

Larsen et al. [69] created an in-line fiber thermo-optic switch by infiltrating a PCF with a LC that undergoes a phase transition close to room temperature. On the external surface of the PCF the researchers coated a conducting layer to form a resistive heater and with only a $0.4^{\circ} \mathrm{C}$ temperature change they demonstrated a switch with a very high extinction ratio of up to $45 \mathrm{~dB}$ at $1600 \mathrm{~nm}$.

As an alternative to tapering a MOF, a LPG can be formed in the fiber core that couples light into the cladding region to produce a narrowband resonance. Mach et al. [70] infused within an air hole a low index (1.28) fluid fully overlapping the LPG together with a high index (1.73) fluid on the edge of the LPG. Separate microheaters adjusted the index of the low index fluid and the position of the high index fluid to independently change the LPG resonance wavelength (over 12 $\mathrm{nm}$ ) and the attenuation strength (up to $15 \mathrm{~dB}$ ) to form a tuneable narrowband filter.

In 2006 Scolari et al. [71] created a tunable optical Gaussian filter by tapering a LC infiltrated PBGF which removed a number of the transmitted passbands to leave a Gaussian-like transmission spectrum in the wavelength range 1200 to $1600 \mathrm{~nm}$. Mathews et al. [72] created a deep optical 
notch filter by applying a perpendicular electric field to a LCfilled PBGF. The filter wavelength position was tuned linearly up to $22 \mathrm{~nm}$ with applied voltage in the range 60 to $110 \mathrm{~V}$ DC. Zou et al. [73] used high index oil (refractive index 1.65) within an erbium-doped PCF to create a thermally actuated notch filter tunable at a rate of $1.3 \mathrm{~nm} /{ }^{\circ} \mathrm{C}$. However, the insertion loss of this device was more than $10 \mathrm{~dB}$. Wei et al. [74] extended the functionality of LC-filled PBGFs by concatenating two PCF fibers infiltrated with different LCs to form a bandpass filter with overlapping tunable spectra. The two fibers were mounted in a V-groove sandwiched between gold electrodes which allowed voltages to be individually applied to each fiber section as required to separately or simultaneously tune each edge of the overlap spectra covering the wavelength range 1520 to $1680 \mathrm{~nm}$. The operating voltage ranged from 90 to $120 \mathrm{~V}$ with a response time under $20 \mathrm{~ms}$.

\section{FIBER OPTOFLUIDIC POLARISERS}

SMF polarizers allow one of the linear orthogonal modes of a SMF to transmit whilst attenuating the other. They find applications in optical networks and sensing systems, and are often used in conjunction with other optical components such as lasers and optical isolators.

\section{A. Continuous Fiber Optofluidic Polarizers}

Optical fiber polarisers are among the oldest fiber optofluidic devices and can be traced back to the work of Ioannidis and Giles in 1988 [75] who employed a LC upon a polished fiber to create a polarizer with extinction ratios $>45$ $\mathrm{dB}$ and an insertion loss of only $0.2 \mathrm{~dB}$. Later, Ma et al. embedded a SPF into silicon wafers with a LC overlay to form an in-line polarizer with an extinction ratio of $42 \mathrm{~dB}$ [76]. Huang et al. [77] applied a photoresponsive LC to demonstrate an optically controllable polarizer with a $2 \mathrm{~Hz}$ optical modulation frequency and an azimuthal angle that could be switched by nearly $35^{\circ}$.

\section{B. MOF Optofluidic Polarizers}

An external electric field applied perpendicularly to a LCfilled PCF was used by Haakestad et al. [78] to orientate the LC molecules and introduce a polarization dependent loss of over $30 \mathrm{~dB}$. Since then other researchers have improved upon the concept. Wei et al. [79] improved the insertion loss associated with splicing PCFs to SMFs down to $2.7 \mathrm{~dB}$ for the complete device by mounting the fibers in $\mathrm{V}$-grooves fabricated on a silicon substrate with SU-8 fiber fixers (Fig. 17). The grooves also contained four separate Au electrodes for applying an electric field to the LC infiltrated into the PCF. The use of four electrodes allowed the electric field to be rotated in steps of $45^{\circ}$ which re-orientated the LC molecules and thus rotated the optical axis of the fiber polarizer, with an extinction ratio of up to $21 \mathrm{~dB}$.

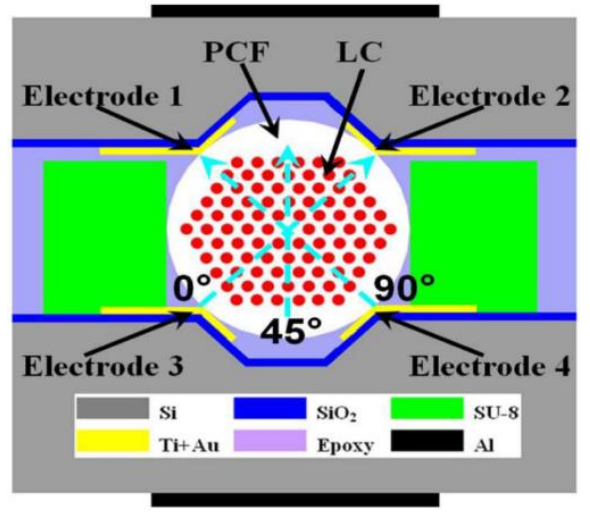

Fig. 17 Cross-section of liquid crystal infiltrated PCF rotatable polarizer showing electric field lines directions (figure reproduced with permission from [79]).

\section{FIBER-OPTOFLUIDICS FOR NON-STANDARD APPLICATIONS}

Finally, as well as creating new formats of traditional optical devices, single-mode fiber optofluidic devices have been applied to more unusual applications. Barbier et al. [80] employed a liquid filled core of a PCF to reduce noise photons during the generation of correlated photon pair sources by four-wave mixing. Traditional silica cores exhibit Raman scattering and generate unwanted uncorrelated photons. This can be overcome by a liquid core filled with deuterated acetone which exhibits narrower Raman spectral lines and also a higher spectral shift allowing rejection of Raman lines outside the transmission bandwidth of the fiber. In another application Ebnali-Heidari et al. [81] proposed that a liquid filled hollow core PCF could be used create a slow-light medium that increases the effective optical path length and thus improves the sensitivity in optical gas sensing. By suitable choice of fluid one can tune the sensor to a particular gas absorption line.

\section{CONCLUSION}

In this paper, we have reviewed the field of single-mode fiber optofluidics which emerges from combining optical fiber technology with fluidics to create new formats of established fiber devices. Overall, the majority of the devices discussed required modification of a standard optical fiber topology which introduces fabrication issues, while some devices have also employed unusual or complex operating conditions.

Fiber-optofluidic magnetometers are numerous, but tend to operate over a linear magnetic field range limited to a few tens of $\mathrm{mT}$, but can have sensitivities of hundreds of $\mathrm{pm} / \mathrm{mT}$. Not unexpectedly, MOF magnetometers generally offer a higher sensitivity than other formats, but the actual sensitivity is a complex interaction of device geometry, sensing method, and magnetic fluid concentration. Two formats of a PCF infiltrated with a MF demonstrated exceptionally high sensitivity over a short magnetic field range. These fiber optofluidic magnetometers can offer an alternative to present fiber optic strain and rotation magnetometers. However, MOFs require complex fabrication which can add to the cost of the sensor. In addition, many optical fibers magnetometers demonstrated are 
often difficult to fabricate and can require expensive interrogation equipment if spectral analysis is employed.

Commercial optical fiber attenuators range from a fixed 3 $\mathrm{dB}$ component to a VOA with a dynamic $80 \mathrm{~dB}$ range. Relatively few fiber optofluidic linear VOAs have been demonstrated, but these achieve variable attenuation ranges from 20 to $63 \mathrm{~dB}$, which is more than adequate for many applications. For this device the fiber gap format naturally lends itself to an appropriate geometry for attenuating light. Compared to VOAs and magnetometers, the actuation of fiber switches can employ quite archaic methods, including thermally generated bubbles, optically generated clusters in a MF, and a temperature induced phase change in a LC.

The overall area of research described as single-mode fiber optofluidics is in its infancy, and is limited by the availability of fluids which have optical properties that can be employed to modify the optical signal in a SMF. These fluids often have large thermo-optical coefficients but very few devices have explored temperature compensation schemes. An issue for all fiber optofluidic devices is environmentally sealing the fluid to reduce evaporation of the fluid, and in this respect oils are preferable to water-based fluids. Sealing the fluid within a MOF is one method, but comes at the expense of increased insertion losses when using a MOF section. Another potential problem for these devices is that some moving fluids can potentially leave a thin residue on a surface that can absorb energy from the optical field and thus affect the reversibility of the device. Combining single-mode fiber optics with fluidics has resulted in many demonstrator devices, and steady research and growth in this field can be expected.

\section{REFERENCES}

[1] V. R. Horowitz, D. D. Awschalom, and S. Pennathur, "Optofluidics: field or technique?," Lab Chip, vol. 8, pp. 1856-63, 2008.

[2] L. Pang et al., "Optofluidic devices and applications in photonics, sensing and imaging," Lab Chip, vol. 12, pp. 3543-3551, 2012.

[3] R. A. Bergh, H. C. Lefevre, and H. J. Shaw, "Single-mode fiber-optic polarizer," Opt. Lett., vol. 5, pp. 479-481, 1980.

[4] C. Hussey and J. Minelly, "Optical fibre polishing with a motor-driven polishing wheel," Electron. Lett., vol. 24, pp. 805-806, 1988.

[5] A. Duduś, R. Blue, and D. Uttamchandani, "Comparative study of microfibre and side-polished optical fibre sensors for refractometry in microfluidics," IEEE Sensors Journal, vol. 13, pp 1594-1601, 2013.

[6] N. Lou et al., "Embedded optical micro/nano-fibers for stable devices," Opt, Lett., vol. 35, pp. 571-573, 2010.

[7] L. Xiao et al., "Stable low-loss optical nanofibers embedded in hydrophobic aerogel," Opt. Exp., vol. 19, pp. 764-769, 2011.

[8] W. Jin et al., "Robust microfiber photonic microcells for sensor and device applications," Opt. Exp., vol. 22, pp. 28132-28141, 2014.

[9] A. M. Vengsarkar et al., "Long-period fibre-grating-based gain equalizers," Opt. Lett., vol. 21, pp. 336-338, 1996

[10] W. Jin, J. Ju, H. L. Ho, Y. L. Hoo, A. Zhang, "Photonic crystal fibers, devices, and applications," Front. Optoelectron. China, vol. 6, pp. 3-24, 2013.

[11] L. Xiao, W. Jin, and M. S. Demokan, "Fusion splicing small-core photonic crystal fibers and single-mode fibers by repeated arc discharges," Opt. Lett., vol. 32, pp. 115-117, 2007.

[12] H. E. Horng et al., "Designing the refractive indices by using magnetic fluids," Appl. Phys. Lett., vol. 82, pp. 2434-2434, 2003.

[13] X. Li, H. Ding, and C. Han, "A novel magnetic field sensor based on the combination use of microfiber knot resonator and magnetic fluid," in Proceedings of the IEEE Int. Conf. Condition Monitoring and Diagnosis (CMD '12), pp. 111-113, September 2012.
[14] A. Layeghi, H. Latifi, and O. Frazão, "Magnetic field sensor based on nonadiabatic tapered optical fibre with magnetic fluid," IEEE Photon. Technol. Lett., vol. 26, pp.1904-1907, 2014.

[15] M. Deng, D. Liu and D. Li, "Magnetic field sensor based on asymmetric optical fibre taper and magnetic fluid," Sens. Actuat., vol. A 211, pp. 55$59,2014$.

[16] Y. Miao et al., "Magnetic field tunability of optical microfibre taper integrated with ferrofluid," Opt. Exp., vol. 21, pp. 29914-29920, 2013.

[17] J. Wu et al., "Magnetic-field sensor based on core-offset tapered optical fibre and magnetic fluid," J. Opt., vol. 16, pp. 075705-5, 2014.

[18] S. Dong, S. Pu, and H. Wang, "Magnetic field sensing based on magnetic-fluid clad fibre-optic structure with taper-like and lateral-offset fusion splicing," Opt. Exp., vol. 22, pp. 19108-19116, 2014.

[19] S. Pu and S. Dong, "Magnetic field sensing based on magnetic-fluidclad fibre-optic structure with up-tapered joints," IEEE Photonics Journal, vol. 6, p. 5300206, 2014.

[20] P. Zu et al., "Magneto-optical fibre sensor based on magnetic fluid," Opt. Lett., vol. 37, pp. 398-400, 2012.

[21] P. Zu et al., "Enhancement of the sensitivity of magneto-optical fibre sensor by magnifying the birefringence of magnetic fluid film with Loyt-Sagnac interferometer," Sensor. Actuat. B-chem., vol. B 191, pp.19-23, 2014.

[22] H. Wang et al., "Magnetic field sensing based on singlemodemultimode-singlemode fibre structures using magnetic fluids as cladding," Opt. Lett., vol. 38, pp. 3765-3768, 2013.

[23] W. Lin et al., "Fibre-optic in-line magnetic field sensor based on the magnetic fluid and multimode interference effects," Appl. Phys. Lett., vol. 103, p. 151101, 2013.

[24] Y. Miao et al., "Magnetic Field Tunability of Square Tapered No-Core Fibres Based on Magnetic Fluid," J. Lightw. Technol., vol. 32, pp. 46004605, 2014.

[25] Y. Chen et al., "Optical fibre magnetic field sensor based on singlemode-multimode-single-mode structure and magnetic fluid," Opt. Lett., vol. 38, pp. 3999-4001, 2013

[26] R. Zhang et al., "U-bent single-mode-multimode-single-mode fibre optic magnetic field sensor based on magnetic fluid," Appl. Phys. Exp., vol. 7, p. 072501-4, 2014

[27] L. Gao et al., "Long-period fiber grating within D-shaped fiber using magnetic fluid for magnetic-field detection," IEEE Photonics Journal, vol. 4, pp. 2095-2104, 2012.

[28] M. Deng et al., "Compact magnetic-field sensor based on optical microfibre Michelson interferometer and $\mathrm{Fe}_{3} \mathrm{O}_{4}$ nanofluid," Appl. Opt., vol. 52, p.734, 2013.

[29] S. Dong, S. Pu, and J. Huang, "Magnetic field sensing based on magneto-volume variation of magnetic fluids investigated by air-gap Fabry-Pérot (FP) fibre interferometers," Appl. Phys. Lett., vol. 103, p. 111907, 2013

[30] R. Q. Lv et al., "Magnetic fluid-filled optical fibre Fabry-Pérot sensor for magnetic field measurement," IEEE Photon. Technol. Lett., vol. 26, p. 217-219, 2014.

[31] Y. Zhao et al., "Fibre optic Fabry-Perot magnetic field sensor with temperature compensation using a fibre Bragg grating," IEEE T. Instrum. Meas., vol. 63, pp. 2210-2214, 2014.

[32] D. Homa and G. Pickrell, "Magnetic sensing with ferrofluid and fibre optic connectors," Sensors, vol. 14, pp. 3891-3896, 2014.

[33] P. Zu et al., "Temperature-insensitive magnetic field sensor based on nanoparticle magnetic fluid and photonic crystal fibre," IEEE Photonics Journal, vol. 4, pp. 491-498, 2012.

[34] P. Zu et al., "Magneto-optical fibre sensor based on bandgap effect of photonic crystal fibre infiltrated with magnetic fluid," Appl. Phys. Lett., vol. 101, p. 241118, 2012.

[35] Y. Miao et al., "Ferrofluid-infiltrated microstructured optical fibre longperiod grating," IEEE Photon. Technol. Lett., vol. 25, no. 3, p. 306-309 (February 1, 2013).

[36] H. V. Thakur et al., "Photonic crystal fibre injected with $\mathrm{Fe}_{3} \mathrm{O}_{4}$ nanofluid for magnetic field detection," Appl. Phys. Lett., vol. 99, p. 161101-3, 2011

[37] R. Gao, Y. Jiang, and S. Abdelaziz, "All-fibre magnetic field sensors based on magnetic fluid-filled photonic crystal fibres," Opt. Lett., vol. 38, pp. 1539-1541, 2013.

[38] Y. Zhao, D. Wu, and R.-Q. Lv, "Magnetic field sensor based on photonic crystal fibre taper coated with ferrofluid," IEEE Photon. Technol. Lett., vol. 27, p. 26-29, 2015. 
[39] Y. Zhao et al., "Hollow-core photonic crystal fibre Fabry-Perot sensor for magnetic field measurement based on magnetic fluid," Opt. Laser Technol., vol. 44, pp. 899-902, 2012.

[40] G. N. Smith et al., "Characterization and performance of a Terfenol-D coated femtosecond laser inscribed optical fibre Bragg sensor with a laser ablated microslot for the detection of static magnetic fields," Opt. Exp., vol. 19, pp. 363-370, 2011.

[41] M. Yang et al., "Optical fiber magnetic field sensors with TbDyFe magnetostrictive thin films as sensing materials," Opt. Exp., vol. 17, pp. 20777-20782, 2009.

[42] S. Mathews, G. Farrell, and Y. Semenova, "LC infiltrated photonic crystal fibres for electric field intensity measurements," Appl. Opt., vol. 50, pp. 2628-2635, 2011.

[43] C. Lee and J. A. Yeh, J. Micro/Nanolith. MEMS MOEMS, vol. 07, p. 021003-1 (2008).

[44] O.Tabata et al., Eds., Reliability of MEMS: Testing of Materials and Devices. New York, NY, USA: Wiley, 2008.

[45] J. Hsieh et al., "Tunable Microfluidic optical-fibre devices based on electrowetting pumps and plastic microchannels," IEEE Photon. Tech. Lett., vol. 15, pp. 81-83, 2003.

[46] B. R. Acharya et al., "Tunable optical fibre devices based on broadband long-period gratings and pumped microfluidics," Appl. Phys. Lett., vol. 83, pp. 4912-4914, 2003.

[47] C. Gu, Y. Xu, and Y. Liu, Fiber based devices for DWDM optical communication systems, information optics and photonics technology, G. Mu, F. T. S. Yu, and S. Jutamulia, Eds., vol. 5642. Bellingham,WA, USA: SPIE, 2005.

[48] A. Duduś et al., "Side-polished fibre optofluidic attenuator based on electrowetting-on-dielectric actuation," Int. Conf. Optical MEMS \& Nanophotonics (OMN), pp. 95-96, Kanazawa, Japan, 18-22 August 2013.

[49] A. Duduś et al., "Modeling and characterization of an electrowetting based single mode fibre variable optical attenuator," IEEE J. Sel. Top. Quant., vol. 21, p. 4500209, 2015.

[50] Y. Hongbin et al., "A variable optical attenuator based on optofluidic technology," J. Micromech. Microeng., vol. 18, p.115016, 2008.

[51] M. I. Lapsley et al., "An in-plane, variable optical attenuator using a fluid-based tunable reflective interface," Appl. Phys. Lett., vol. 95, p. 083507, 2009.

[52] S. A. Reza and N. A. Riza, "A liquid lens based broadband variable fibre optical attenuator," Opt. Commun., vol. 282, pp. 1298-1303, 2009.

[53] S. A. Reza and N. A. Riza, "High dynamic range variable fibre-optical attenuator using digital micromirrors and opto-fluidics," IEEE Photon. Technol. Lett., vol. 21, pp.845-847, 2009.

[54] S. Xu et al., "Polarization independent VOA based on dielectrically stretched LC droplet," Opt. Exp., vol. 20, pp.17059-17064, 2012.

[55] A. Duduś, R. Blue, and D. Uttamchandani, "Single mode fibre variable optical attenuator based on a ferrofluid shutter," Appl. Opt., vol. 54, pp. 1952-1957, 2015.

[56] C. Kerbage et al., "Integrated all-fiber variable attenuator based on hybrid microstructure fiber," Appl. Phys. Lett., vol. 79, pp. 3191-3193, 2001.

[57] E. C. Mägi, H. C. Nguyen, and B. J. Eggleton, "Air-hole collapse and mode transitions in microstructured fiber photonic wires," Opt. Exp., vol. 13, pp. 453-459, 2005.

[58] C. Kerbage and B. J. Eggleton, "Manipulating light by microfluidic motion in microstructured optical fibers," Optical Fiber Technology, vol. 10, pp. 133-149, 2004.

[59] S. Mathews, G. Farrell, and Y. Semenova, "Experimental demonstration of an all-fibre variable optical attenuator based on LC infiltrated photonic crystal fibre," Microw. Opt. Techn. Lett., vol. 53, pp. 539-543, 2011.

[60] C. Marxer and N. F. de Rooij, "Micro-opto-mechanical 2x2 switch for single-mode fibers based on plasma-etched silicon mirror and electrostatic actuation," J. Lightw. Technol., vol. 17, pp. 2-6, 1999.

[61] K. McCallion, W. Johnstone, and G. Thursby, "Investigation of optical fibre switch using electro-optic interlays," Electron. Lett., vol. 28, pp. 410-411, 1992.

[62] L.W. Shacklette et al., "High performance thermo-optic switches based on low-loss acrylate polymers," Opt. Eng., vol. 42, pp. 2841-2849, 2003.

[63] R. A. Soref, "Liquid-crystal fibre-optic switch," Opt. Lett., vol. 4, pp. 155-157, 1979

[64] N. A. Riza, "High-speed high-isolation 2x2 fiber-optic switch for wideband radar photonic beamforming controls," J. Lightw. Technol., vol. 26, pp. 2500-2505, 2008.
[65] J. Yu et al., "All-optically reconfigurable and tunable fibre surface grating for in-fibre devices: a wideband tunable filter," Opt. Exp., vol. 22, pp. 5950-5961, 2014.

[66] J. E. Fouquet et al., "A compact, scalable cross-connect switch using total internal reflection due to thermally-generated bubbles," IEEE Lasers and Electro-Optics Society (LEOS '98), vol.2, pp. 169-170, 1998.

[67] Q.-F. Dai et al., "All-optical switching mediated by magnetic nanoparticles," Opt. Lett., vol. 35, pp. 97-99, 2010.

[68] L. Brandhoff et al., "Optofluidic multiplexing and switching device," IEEE 17th International Conference on Transducers \& Eurosensors, pp. 2329-2332 (2013).

[69] T. T. Larsen et al., "Thermo-optic switching in LC infiltrated photonic bandgap fibres," Electron. Lett., vol. 39, pp. 1719-1720, 2003.

[70] P. Mach et al., "Tunable microfluidic optical fiber," Appl. Phys. Lett., vol. 80, pp. 4294-4296, 2002.

[71] L. Scolari, T. T. Alkeskjold, and A. Bjarklev, "Gaussian filtering with tapered liquid crystal photonic bandgap fibres," IEEE Lasers and Electro-Optics Society (LEOS 2006), pp. 829-830, 2006.

[72] S. Mathews, Y. Semenova, and G. Farrell, "Electronic tunability of ferroelectric LC infiltrated photonic crystal fibre," Electron. Lett., vol. 45, pp. 617, 2009.

[73] B. Zou et al., "Deep notch filter based on liquid-filled photonic crystal fibre," Front. Optoelectron. China, vol. 3, pp. 289-291, 2010.

[74] L. Wei, T. T. Alkeskjold, and A. Bjarklev, "Electrically tunable bandpass filter based on lc photonic bandgap fibres," Conference on OFC/NFOEC, pp. 1-3, 2010.

[75] Z. K. Ioannidis and I. P. Giles, "LC all-fibre optical polarizer," Electron. Lett., vol. 24, pp. 1453-1455,1988.

[76] S. P. Ma and S. M. Tseng, "High-performance side-polished fibres and applications as LC clad fibre polarizers," J. Lightw. Technol., vol. 15, pp. 1554-1558, 1997.

[77] C.-Y. Huang, W.-H. Fu, and V. K. S. Hsiao, "Optically switchable allfibre optic polarizer," IEEE Photonics Global Conf. (PGC), pp. 1-2, Singapore, 13-16 Dec. 2012.

[78] M. W. Haakestad et al., "Electrically tunable photonic bandgap guidance in a liquid-crystal-filled photonic crystal fibre," IEEE Photon.Technol. Lett., vol 17, pp. 819-821, 2005.

[79] L. Wei, T. T. Alkeskjold, and A. Bjarklev, "Compact design of an electrically tunable and rotatable polarizer based on a LC photonic bandgap fiber," IEEE Photon. Technol. Lett., vol. 21, pp. 1633-1635, 2009).

[80] M. Barbier, I. Zaquine, and P. Delaye, "Generation of correlated photon pairs by spontaneous four-wave mixing in liquid-core microstructured fibres," Optical Communications (ECOC 2014), pp. 1-3, 2014.

[81] M. Ebnali-Heidari et al. "Designing tunable microstructure spectroscopic gas sensor using optofluidic hollow-core photonic crystal fibre," IEEE J. Quantum Elect., vol. 50, pp. 943-950, 2014.

Robert Blue received the Ph.D. degree in optical electronics from the University of Strathclyde, Glasgow, U.K., in 1996. He is currently at the Centre for Microsystems and Photonics, University of Strathclyde. His current research interests span chemical and biomedical sensors using optical and electrical measurement techniques.

Anna Duduś received the MSc degree in Electronics (specialization in microsystems) from the Wroclaw University of Technology, Poland in 2010. She is currently working toward the $\mathrm{PhD}$ degree at the Dept. of EEE in the Centre for Microsystems and Photonics of the University of Strathclyde, Glasgow, UK. Her research areas include optofluidic devices and applications.

Deepak Uttamchandani (SM'05) received his $\mathrm{PhD}$ degree from University College London, London, UK in 1985 for research in the areas of optical fiber sensors and optical frequency domain reflectometry. He is currently the Head of the Centre for Microsystems and Photonics, University of Strathclyde, Glasgow, UK. His early research in MEMS concentrated on opto-thermal microresonator sensors and in investigating techniques for MEMS material characterization using micromechanical resonators. His recent research has concentrated on system applications of optical MEMS including intra-cavity MEMS-based laser systems, MEMS-based directional microphones and MEMS-based single-pixel imaging systems. He has also published in the fields of optofluidic devices, optical sensors, including sub-wavelength tipbased Raman spectroscopy, and in situ intraocular drug detection systems via optical spectroscopy in the eye. In 2014 he organized and chaired the IEEE Optical MEMS and Nanophotonics conference (Glasgow, UK).. 